\title{
Does daytime sleepiness alter visual memory in schoolchildren aged 9 to 11 at different times during the school semester?
}

\author{
A sonolência diurna altera a memória visual em escolares entre 9 e 11 anos em momentos diferentes \\ do período letivo?
}

¿Altera la somnolencia diurna la memoria visual en escolares de 9 a 11 años en diferentes momentos del curso escolar?

Received: 09/01/2021 | Reviewed: 09/08/2021 | Accept: 09/11/2021 | Published: 09/13/2021

\author{
Lívia Maria de Lima Leôncio \\ ORCID: https://orcid.org/0000-0001-9725-7061 \\ Faculdade Venda Nova Imigrante, Brazil \\ E-mail: livia.lm1119@gmail.com \\ Flávio Henrique de Santana \\ ORCID: https://orcid.org/0000-0001-7851-8975 \\ Universidade Federal de Pernambuco, Brazil \\ E-mail: flvshenrique@gmail.com \\ Clécia Gabriela Bezerra \\ ORCID: https://orcid.org/0000-0002-3747-7713 \\ Universidade Federal de Pernambuco, Brazil \\ E-mail: clecia.bezerra@ufpe.br \\ Gilberto Ramos Vieira \\ ORCID: https://orcid.org/0000-0002-5155-3532 \\ Universidade Federal de Pernambuco, Brazil \\ E-mail: gilberto_r.2010@hotmail.com \\ Letycia dos Santos Neves \\ ORCID: https://orcid.org/0000-0003-2286-7986 \\ Universidade Federal de Pernambuco, Brazil \\ E-mail: letycia.sneves@gmail.com \\ Ana Carolina da Silva Reis \\ ORCID: https://orcid.org/0000-0002-5397-7021 \\ Universidade Federal de Pernambuco, Brazil \\ E-mail: a.k.w16@hotmail.com \\ Débora Laís Chaves Gomes \\ ORCID: https://orcid.org/0000-0003-3609-3774 \\ Universidade Federal de Pernambuco, Brazil \\ E-mail: laisdebora089@gmail.com \\ Tamyres Tavares Santos \\ ORCID: https://orcid.org/0000-0002-2312-5450 \\ Universidade Federal de Pernambuco, Brazil \\ E-mail: tamyres_ts@hotmail.com \\ Mírian Celly Medeiros Miranda David \\ ORCID: https://orcid.org/0000-0002-7152-8852 \\ Universidade Federal de Pernambuco, Brazil \\ E-mail: miriancelly@hotmail.com \\ Rhowena Jane Barbosa de Matos \\ ORCID: https://orcid.org/0000-0001-5914-7304 \\ Universidade Federal do Recôncavo da Bahia, Brazil \\ E-mail: rhowena.matos@ufrb.edu.br
}

\begin{abstract}
Daytime sleepiness could reduce the memorization of children who are in school. Thus, the aim of this study was to study the effect of daytime sleepiness on the visual memory of schoolchildren at different times during the school semester. Individuals of both genders $(n=88)$ aged 9 to 11 years and regularly enrolled at the Mariana Amália Municipal School were selected. Data collection occurred in two moments: at the beginning and end of the academic semester. A semi-structured questionnaire was used to collect sociodemographic information, the Epworth Sleepiness Scale to assess sleepiness and the Rey-Osterrieth complex figure, object recall, scrambling figures and addition of dictated numbers for memory analysis tests. The data revealed that there is no direct relationship between sleepiness and impaired memory by the tests used in any of the analyzed moments. However, children showed lower visuospatial memory efficiency at the beginning of the school semester, indicating that they may have greater difficulty in memory
\end{abstract}


retention. Lastly, there was an abnormality in the degree of sleepiness at the end of the school semester and the female gender showed efficiency in immediate and late memory.

Keywords: Memory; Sleepiness; Children; Students.

\section{Resumo}

A sonolência diurna pode reduzir a memorização de informações de crianças que estão no ambinte escolar. Assim, objetivou-se estudar o efeito da sonolência diurna sobre a memória visual de escolares. Foram selecionados indivíduos de ambos os sexos $(\mathrm{n}=88)$, regularmente matriculados na Escola Municipal Mariana Amália, com idade entre 9 a 11 anos. A coleta de dados ocorreu em dois momentos: início e final do semestre letivo. Utilizou-se um questionário semiestruturado para coleta de informações sociodemográficas, a Escala de Sonolência de Epworth para avaliar a sonolência e os testes da figura Complexa de Rey, Recordação de objetos, figuras embaralhas e adição de números ditados para análise da memória. Os dados revelaram que não há relação direta entre sonolência e comprometimento da memória pelos testes utilizados em nenhum dos momentos analisados. Entretanto, no início do semestre letivo, as crianças apresentaram menor eficiência da memória visuoespacial, indicando que podem ter maior dificuldade na retenção da memória. No final do semestre, houve anormalidade no grau de sonolência e o sexo feminino apresentou eficiência na memória imediata e tardia.

Palavras-chave: Memória; Sonolência; Criança; Estudantes.

\section{Resumen}

La somnolencia diurna puede reducir la memorización de informaciones en los niños que están en el ambiente escolar. Así, se propuso estudiar el efecto de la somnolencia diurna en la memoria visual de escolares. Se seleccionaron individuos de ambos sexos $(\mathrm{n}=88)$, regularmente matriculados en la Escuela Municipal Mariana Amália, con edades comprendidas entre 9 y 11 años. La recogida de datos se produjo en dos momentos: al principio y al final el semestre escolar. Se utilizó un cuestionario semiestructurado para recoger información sociodemográfica, la Escala de Somnolencia de Epworth para evaluar la somnolencia y las pruebas de la figura compleja de Rey, recuerdo de objetos, figuras barajadas y suma de números dictados para el análisis de la memoria. Los datos revelaron que no existe una relación directa entre somnolencia y el deterioro de la memoria por las pruebas utilizadas en cualquiera de los momentos analizados. Sin embargo, al principio del semestre escolar, los niños mostraron una menor eficiencia en la memoria visoespacial, lo que indica que pueden tener una mayor dificultad en la retención de la memoria. Al final del semestre, hubo una anormalidad en el grado de somnolencia al final del semestre escolar y el sexo femenino mostró eficiencia en la memoria inmediata y tardía.

Palabras clave: Memoria; Somnolencia; Niño; Estudiantes.

\section{Introduction}

Excessive daytime sleepiness is a problem which mainly affects children and adolescents and can be characterized by a greater feeling of need for sleep and lesser alertness (Macchitella et al., 2020). Studies point to insufficient sleep as one of the main factors that contribute to difficulty in maintaining a desirable awake state during the day (Gustafsson et al., 2016; Mah et al., 2018). Lifestyle and some environmental factors affect sleep quality and duration, which can cause insufficiency (Sinha et al., 2015). Some examples are the time to wake up to go to school, food, noises during the night, inadequate temperature and an excess of light during sleep (Macchitella et al., 2020). In addition, studies show that children adopt the same habits as adults, increasing the use of electronic devices at night (Lissak, 2018; Uebergang et al., 2017).

These changes in children's lifestyles lead to new habits, significantly reducing sleep hours (Lissak, 2018; Uebergang et al., 2017). A loss of sleep regularity impairs functions such as adequate physical growth, body homeostasis and maintenance of cognitive functions, especially memory consolidation (Gustafsson et al., 2016).

Memory is one of the cognitive functions, being defined as a fundamental ability to adapt behavior due to constant environmental changes (Mourão \& Faria, 2015; Rasch \& Born, 2013). A considerable percentage of human memories are acquired through vision which are processed, stored, and evoked through specific neural activation mechanisms (Meyer \& Rust, 2017). These mechanisms can be reduced due to poor sleep quality (Wang et al., 2017), especially in childhood (Heins et al., 2007).

Memory consolidation is a cellular process of reactivation and redistribution of hippocampal-dependent memories to 
neocortical sites which occur during non-REM sleep (Diekelmann \& Born, 2010). However, the resulting REM sleep stabilizes transformed memories (Rasch \& Born, 2013). These two phases play an important role in brain development, thus favoring learning, consolidation and integration of memory-related phenomena (Tononi \& Cirelli, 2014).

Childhood is a phase of rapid brain development with changes in the internal organization of sleep. Changes regarding sleep progressively occur during the first year of life due to biological rhythms maturing. Therefore, newborns who slept most of the time decrease their sleeping hours over the months and start to sleep more at night. Behavioral changes related to sleep throughout development can vary and can cause concerns, especially for parents (Bathory \& Tomopoulos, 2017).

According to Bathory (2017), sleep recommendations vary according to the development stage. A sleep period per night can vary from approximately 9 to 10 hours for school-age children, but they usually sleep less than recommended. This can lead to low school performance (Heins et al., 2007).

Studies show that the quality and quantity of sleep affect the performance of tasks involving memory in children, but these aspects regarding the sleep habits of schoolchildren have not been sufficiently studied (Canet, 2010). Schoolchildren are in a period of life in which they constantly receive a lot of information that requires efficient coding, consolidation and retrieval processes. Furthermore, childhood is a critical stage of development and changes in this period can have repercussions throughout life (van der Heijden et al., 2018).

Research on current sleep habits may enable creating efficient strategies and actions to improve children's health and school performance. In addition, problems associated with sleep can be avoided through interventions before adolescence when there is a lot of vulnerability to sleep changes. Thus, it is hypothesized that excessive daytime sleepiness reduces the efficiency of visual memory in schoolchildren, interfering with the performance of cognitive tasks. Therefore, the aim of this study was to investigate the effect of daytime sleepiness on the visual memory of schoolchildren aged between 9 and 11 years old at different times during the school semester.

\section{Materials and methods}

\subsection{Study design, population and sample}

As for the applied methodology, this was a cross-sectional study (Bastos \& Duquia, 2007) with a quantitative and qualitative approach (Pereira et al., 2018) carried out with children enrolled at the Mariana Amália municipal school in Vitória de Santo Antão - PE, Brazil. The tests were performed twice, at the beginning of the semester (August) and at the end of the semester (November) 2019. All research procedures were conducted at the school between classes.

The study population was formed by a single group according to the inclusion criteria: children between 9 and 11 years and 11 months, of both genders, who agreed to participate in the research. The exclusion criteria included: presence of physical disabilities and cognitive disorders.

All procedures were in accordance with the Regulatory Guidelines and Norms for Research Involving Human Beings (196/96) edited by the National Health Commission, which met the recommendations of Resolution 466/12. The research was approved by the Human Research Ethics Committee under the protocol: CAAE 11628019.1.0000.5208.

\subsection{Sample design and procedures}

The application of the tests was divided into two moments; the first moment of which was carried out in two days at the beginning of the semester (in August) and the second moment in two days at the end of the semester (in November):

The beginning of the semester was considered the first moment (M1): The Epworth Sleepiness Scale and the memory tests, consisting of the Rey-Osterrieth Complex Figures Test, Object recall and Scrambled Figures, were applied. In addition, the perceptual speed in mathematical reasoning was evaluated with the Addition of dictated numbers test. 
The end of the semester was considered the second moment (M2): The Epworth Sleepiness Scale and the Scrambled Objects and Objects Recall tests were applied again at the end of the academic semester.

\subsection{Sociodemographic and clinical characterization}

The individuals eligible for the survey answered a semi-structured questionnaire to collect sociodemographic (age, gender, education) and clinical information (general clinical status, list of medications in use and self-reported pathologies), with the following clinical conditions being considered: heart disease, high blood pressure systemic, cerebrovascular diseases, diabetes mellitus, cancer, neurodegenerative diseases and diseases of the respiratory system.

\subsection{Daytime sleepiness assessment}

The Epworth Sleepiness Scale, developed by Dr. Murray Johns (1991) is a widely used tool to measure the degree of daytime sleepiness. The test was applied prior to the memory tests, andcarried out with each child in the morning in a room provided by the school. Respondents were asked about their perception of their tendency to fall asleep in eight different situations on a scale ranging from 0 (never slept) to 3 (a high risk of falling asleep). A result of up to 9 points indicates a condition considered normal (Johns, 1991). Data were expressed as minimum, median and maximum of the children's total score or in relation to gender at the beginning and end of the school semester.

\subsection{Analyzes of visuospatial memory through different methods}

\subsubsection{Memory assessment and copying strategy}

The Rey-Osterrieth Complex Figure test (Jamus \& Mäder, 2005) was performed with each child in the morning. The evaluator asked the child to look at the figure and make the copy on a sheet; then they asked the child to make the drawing again after an interval of 3 minutes, but this time only based on the figure's memory, which we call evocation. The time when the child observed the figure until they started drawing was recorded using a stopwatch and called the latency time. The time for copying and evoking the figure was also recorded. Five pencil colors were used for the copy drawing, where the child was asked to change the pencil color as soon as some elements were drawn. Data were expressed as mean and standard deviation of time in seconds for each stage of the figure regarding gender and age at the beginning of the school semester.

The manual established by Osterrieth was used for the quantitative and qualitative evaluation. A score of 0 to 2 points was given to each of the 18 items which compose the figure according to the precision and positioning of the drawn item. An analysis of the strategy used to make the copy of the drawing was also performed based on seven types of different ways of starting the drawing. It is presumed that the evocation of memory is best performed when the copy of the figure is carried out in an organized manner.

\subsubsection{Memory assessment using images of objects of the British Capacity Scale}

Children were tested individually using the Object Recall test of the British Capacity Scale (Elliott, CD; Smith, P; Mcculloch, [s.d.]). Each child had 30 seconds to view a card with pictures of 15 objects, after which they had 60 seconds to verbally recall as many objects as possible, a measure of immediate memory (I). Late memory (L) was assessed after 3 minutes, in which verbal recall of the largest possible number of objects was requested again. Data were expressed as mean and standard deviation of the number of correct answers at both times in relation to gender and age.

\subsubsection{Memory assessment using scrambled figures}

The scrambled figure test consisted of identifying and memorizing figures in an image that contained several 
scrambled figures. An image containing several packaged objects was presented on a printed sheet, and the children had 60 seconds to memorize the objects. After 60 seconds, they immediately had to register the names of the memorized objects within 60 seconds. Test time: 2 min. Testing components of visual attention, perceptual speed and flexibility. The score was the number of figures correctly identified (Fadda et al., 2012). Data were expressed as mean and standard deviation of the number of correct answers at both times in relation to gender and age.

\subsubsection{Memory evaluation with numerical addition test}

The test for adding dictated numbers was only performed at the beginning of the school semester due to a reform in the school. The researcher dictated ten mathematical problems of addition at a speed of one number per second. The children then wrote down the answer on a legal sheet. Up to three numbers were dictated per problem (i.e. $2+5+3$ ). The maximum value of the sum was 10. This test measures the perceptual speed and the automaticity of the application of arithmetic operations. The score was the number of correctly solved problems (Fadda et al., 2012). Data were expressed as mean and standard deviation of the number of correct answers in relation to gender at the beginning of the academic semester.

\subsection{Data analysis}

A descriptive data analysis was performed using absolute and relative frequencies for categorical variables and measures of central tendency (median, minimum and maximum) or dispersion (mean and standard deviation) for numerical variables, as well as the percentage of averages. The results are displayed in the form of figures and tables.

The normality of data distribution was analyzed using the Kolmogorov-Smirnov test. Significant differences for data which had a normal distribution were assessed by the Student's t-test. The ANOVA post-hoc variance test and Tukey test were used to compare more than two groups. In addition, Mann-Whitney tests (for comparison between two groups), KruskallWallis test (for comparison between more than two groups), post-hoc: Dunn's or the Wilcoxon paired test were used for nonparametric data. The significance level was set at $\mathrm{p} \leq 0.05$. Statistical analyzes were performed using the GraphPad Prism program (version 8.2).

\section{Results}

\subsection{Sociodemographic and clinical profile}

After applying the eligibility criteria, the sample culminated in 88 participants, composed by $55.7 \%$ females and 44.3\% males. Not all participants performed all tests at both times (beginning and end of the academic semester) due to being absent on the day of assessment or an impossibility to leave the classroom at the collection time.

Regarding age, $22.2 \%$ of the participants were 9 years old, $50.6 \%$ were 10 years old and $27.2 \%$ were 11 years old. A total of $20.5 \%$ of the participants claimed to have health problems, $2.3 \%$ had some physical or mental disability, $17.0 \%$ had restrictions on some food, and 3.4\% were using medication. In addition, $100 \%$ of the participants lived in Vitória de Santo Antão-PE, Brazil.

\subsection{Degree of sleepiness}

At the beginning of the semester (moment 1 - M1), 16 of 69 participants had a degree of normal sleepiness, 26 had moderate sleepiness, 26 abnormal sleepiness and 1 participant presented severe sleepiness. There was a change in this profile at the end of the semester (moment 2 - M2), as 19 of 58 participants had a degree of normal sleepiness, 5 participants had moderate sleepiness, and 34 presented abnormal sleepiness (Figure 1). 
Figure 1 - Assessment of the degree of sleepiness in schoolchildren aged 9 to 11 years.

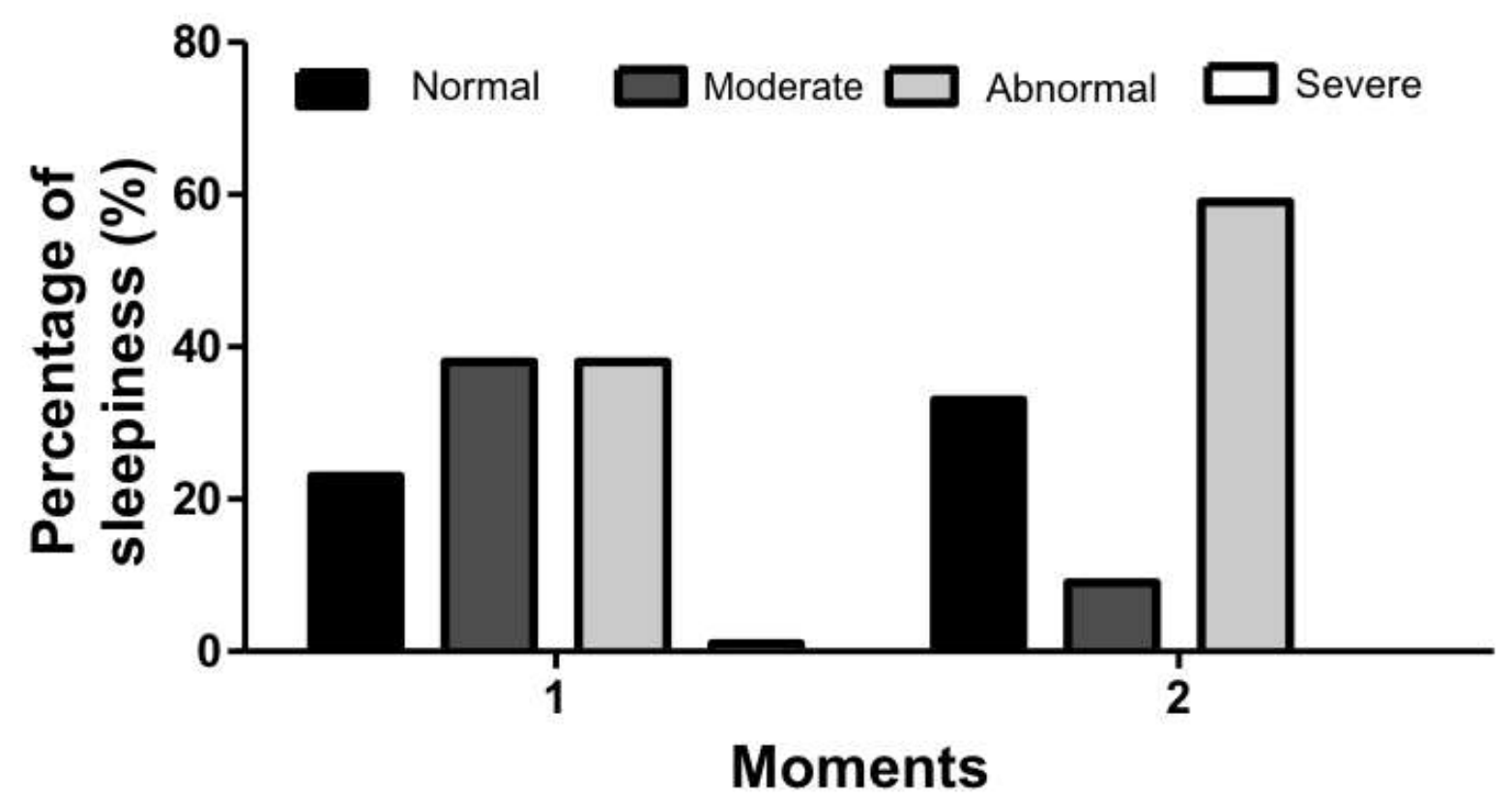

At time $1(n=69)$ and at time $2(n=58)$. Data expressed as a percentage of the average.

When comparing the degree of sleepiness between the students' ages, there was a tendency to decrease at M2 between the ages of 9 and 10 years $(p=0.06)$. There was no significant difference $(p>0.05)$ regarding gender $($ Table 1$)$.

Table 1 - Comparison of the degree of sleepiness between ages and gender at the beginning and end of the school semester.

\begin{tabular}{lll}
\hline Age/Gender & $\begin{array}{l}\text { Moment 1 } \\
\text { minimum; median; maximum (n) }\end{array}$ & $\begin{array}{l}\text { Moment 2 } \\
\text { minimum; median; maximum } \\
(\mathbf{n})\end{array}$ \\
\hline $\mathbf{9}$ years & $0.0 ; 1.5 ; 3.0(12)$ & $0.0 ; 0.0 ; 2.0(11)^{\mathrm{a}}$ \\
$\mathbf{1 0}$ years & $0.0 ; 1.0 ; 2.0(26)$ & $0.0 ; 2.0 ; 2.0(24)$ \\
$\mathbf{1 1}$ years & $0 ; 0 ; 1.0 ; 2.0(13)$ & $0.0 ; 2.0 ; 2.0(12)$ \\
Female & $0.0 ; 1.0 ; 2.0(23)$ & $0.0 ; 1.0 ; 2.0(27)$ \\
Male & $0.0 ; 1.0 ; 3.0(28)$ & $0.0 ; 2.0 ; 2.0(26)$ \\
\hline
\end{tabular}

Results expressed according to the analyzes carried out by comparison according to age, the Kruskall-Wallis test and the Dunn's Multiple post hoc test: ap $=0.06$ (at Moment 2), and the Mann Whitney test between the genders $(p>0.05$ ). Source: Authors.

\subsection{The spatial and visual memories evaluated by the Rey-Osterrieth complex figure test}

The sample that underwent the Rey-Osterrieth Complex Figure test culminated in 42 female students (51.9\%) and 39 male students $(48.1 \%)$. Seven participants were absent for the test application. The test was only applied at time M1, as the school had to advance the end of the school term due to structural reforms and we did not have time to apply the test.

Regarding the copying strategy of the Rey-Osterrieth Complex Figure Test, most of the sample (both female and male) started copying the figure by details included in the frame using the Type 2 strategy (Figure 2a). The Type 2 strategy also predominated when categorizing between ages (Figure $2 b$ ). 
Figure 2 - Copy type strategy of the Rey-Osterrieth Complex Figure according to gender and age.

a)

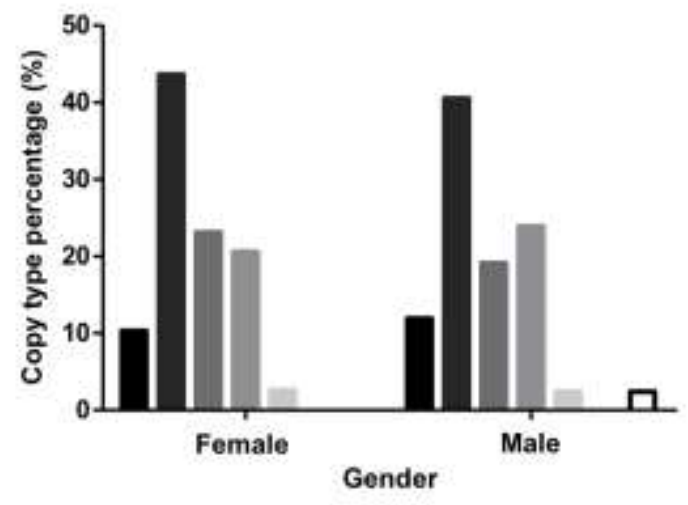

'b)

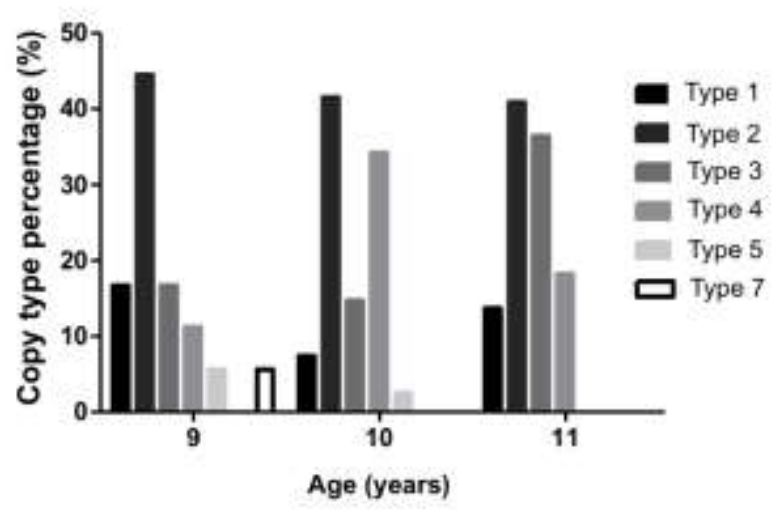

Results expressed by the percentage of the average points according to each copy strategy. Considering (a) the female $(\mathrm{n}=42)$ and male $(\mathrm{n}=$ $39)$; and $(b)$ the ages of $9(n=18), 10(n=41)$ and $11(n=22) . n=$ sample number. Source: Authors.

There was no significant difference between ages $(p>0.05)$ or between gender $(p>0.05)$ when evaluating the observation latency before copying the Rey-Osterrieth complex figure (Table 2). The same result was found when analyzing the time to copy the Rey figure, with no significant difference between ages $(p>0.05)$ or between gender $(p>0.05)($ Table 2$)$.

Comparisons were also made regarding the time to evoke the memory of the Rey figure; in this phase, the students drew the figure again after an interval of three minutes from the copy, with no significant difference between ages ( $p>0.05$ ) or between gender $(\mathrm{p}>0.05)$ (Table 2$)$.

The participants had an average of 22.6 points in the copy and 9.6 points in the evocation. The latency time to initiate the copy was 25.2 seconds on average, while the copy time was 303.4 seconds and memory recall was 192.6 seconds.

Table 2 - Latency time, copy and evocation of the Rey-Osterrieth Complex Figure.

\begin{tabular}{llll}
\hline Age/Gender & $\begin{array}{l}\text { Latency } \\
\text { mean } \pm \text { s.d. }(\mathbf{n})\end{array}$ & $\begin{array}{l}\text { Tempo de cópia } \\
\text { mean } \pm \text { s.d. }(\mathbf{n})\end{array}$ & $\begin{array}{l}\text { Tempo de evocação } \\
\text { mean } \pm \text { s.d. (n) }\end{array}$ \\
\hline $\mathbf{9}$ anos & $8.1 \pm 5.5(17)$ & $296.7 \pm 101.8(18)$ & $164.9 \pm 88.6(18)$ \\
$\mathbf{1 0}$ anos & $7.8 \pm 5.3(38)$ & $322.0 \pm 119.8(41)$ & $209.3 \pm 109.1(41)$ \\
$\mathbf{1 1}$ anos & $7.8 \pm 6.4(21)$ & $272.7 \pm 92.1(22)$ & $190.9 \pm 91.9(22)$ \\
Feminino & $10.6 \pm 12.2(40)$ & $298.6 \pm 112.8(42)$ & $186.4 \pm 97.7(42)$ \\
Masculino & $7.6 \pm 5.0(38)$ & $307.7 \pm 107.7(39)$ & $97.72 \pm 104.5(39)$ \\
\hline
\end{tabular}

Results expressed in accordance with the analyzes carried out using the Kruskall-Wallis test between age and Dunn's Multiple post hoc test ( $p>0.05$ ), and the Mann-Whitney test between the genders ( $>0.05)$. Source: Authors.

\subsection{Visual memory through the object recall test}

The recall test using a card with 15 objects showed that children had a lower number of correct answers in late memory in M1 (I: $7.7 \pm 1.87$; L: $6.4 \pm 2.3$; p<0.0001) (Figure 3). However, there was no significant difference in the number of correct answers in $\mathrm{M} 2$ between the evaluations ( $\mathrm{I}: 6.9 \pm 2.2 ; \mathrm{L}: 6.5 \pm 2.4 ; \mathrm{p}=0.16$ ). 
Figure 3 - Number of correct objects recalled immediately and late at the beginning of the school semester.

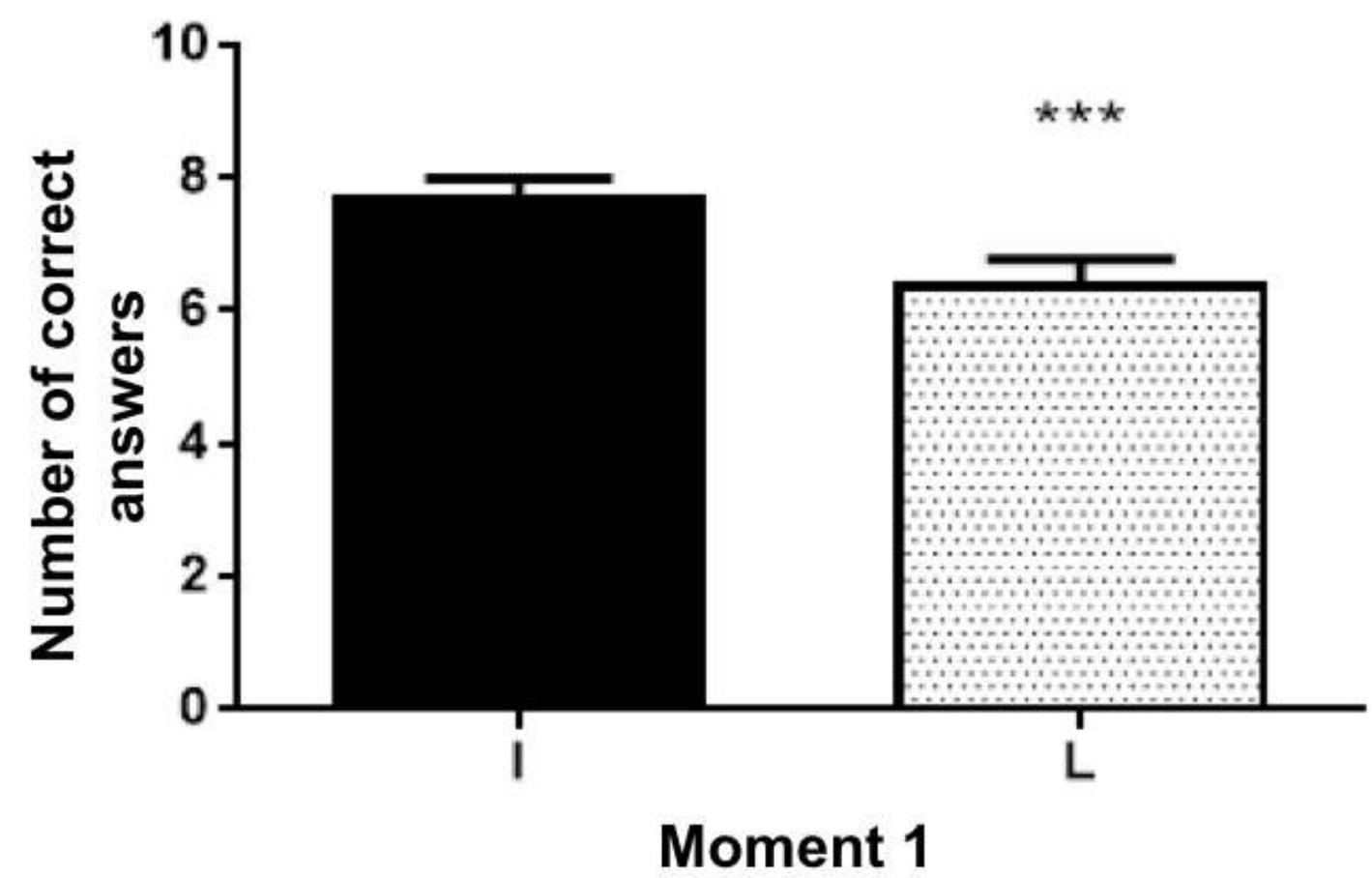

Data expressed as an average of the number of correct answers, Wilcoxon test, $* * * \mathrm{p}<0.001$. I $=$ Immediate memory; $\mathrm{L}=\mathrm{Late}$ memory, $\mathrm{n}=$ 52. Source: Authors.

There was a reduction in correct answers of the figures at M2 in the aspect of immediate memory when comparing the number of correct answers during the evaluation of the immediate and late memory among the female participants (I1: $8.2 \pm$ 1.6; I2: $6.7 \pm 1.8 ; \mathrm{n}=23 ; \mathrm{p}=0.013$ ) (Figure $4 \mathrm{a}$ ). In contrast, late visual memory in males showed a reduction of correct answers only at M1 (I: $7.3 \pm 2.0 ; \mathrm{L}: 5.7 \pm 2.3 ; \mathrm{n}=29 ; \mathrm{p}=0.02)$ (Figure $4 \mathrm{~b})$.

Figure 4 - Number of correct objects recalled by female (a) and male (b) students immediately (I) and late (L) at the beginning and end of the school semester.

a)

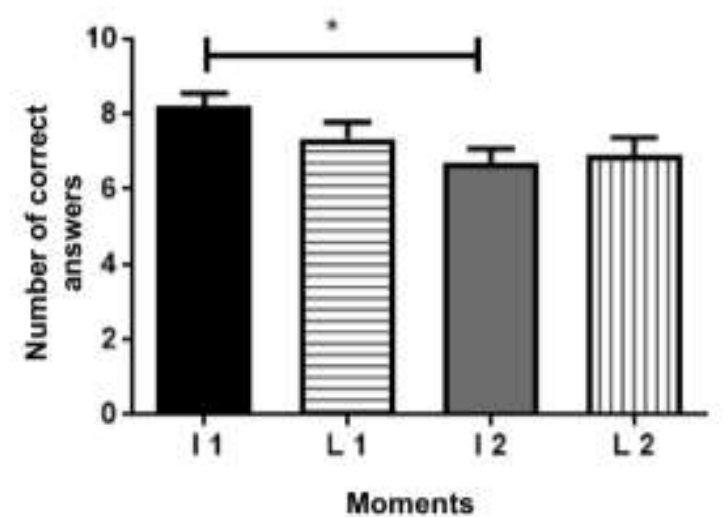

b)

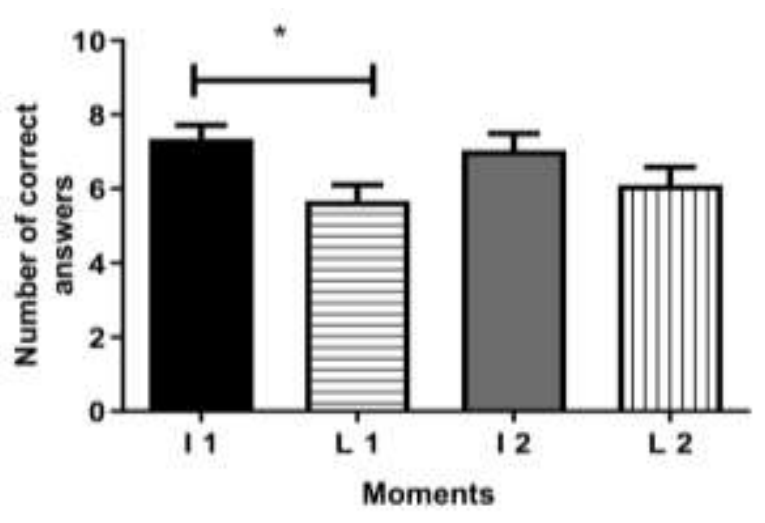

Data expressed as the average number of correct answers, Kruskal-Wallis test and post hoc Dunn's Multiple Comparison, $* \mathrm{p} \leq 0.05 ; \mathrm{n}=23$ (a) and $\mathrm{n}=29$ (b). I 1 = Immediate memory at moment 1; L 1 = Delayed memory at time 1; I 2 = Immediate memory at moment 2; L $2=$ delayed memory at time 2 . Source: Authors.

There was a reduction in the correct answers for immediate memory at the beginning of the semester for males when comparing the number of correct answers of the figures between genders in both evaluation moments (IF: $8.2 \pm 1.6$ vs IM: 7.3 
$\pm 2.0 ; \mathrm{p}=0.049)$. There was also a reduction for the male group in M1 regarding late memory (LF: $7.3 \pm 2.1 \mathrm{vs}$. LM: 5.7 \pm 2.3 ; $\mathrm{p}=0.009)$ (Figure 5).

Figure 5 - Number of correct objects recalled by schoolchildren of both genders immediately (I) and late (L) at the beginning of the semester (M1).

a) Immediate Memory

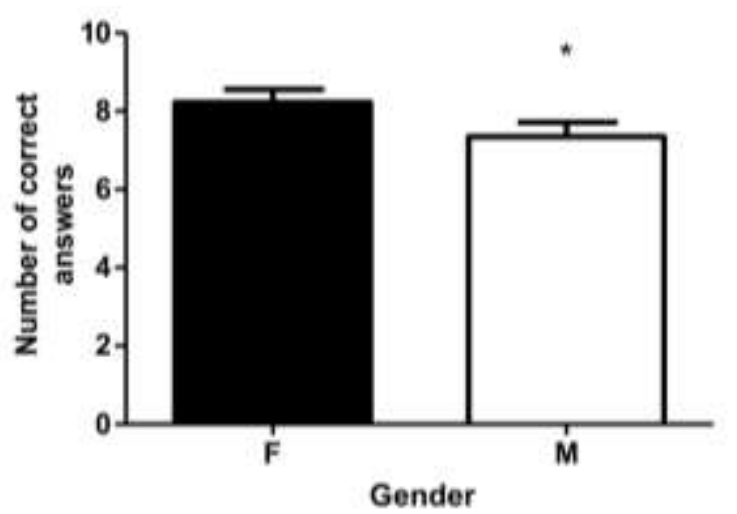

b)

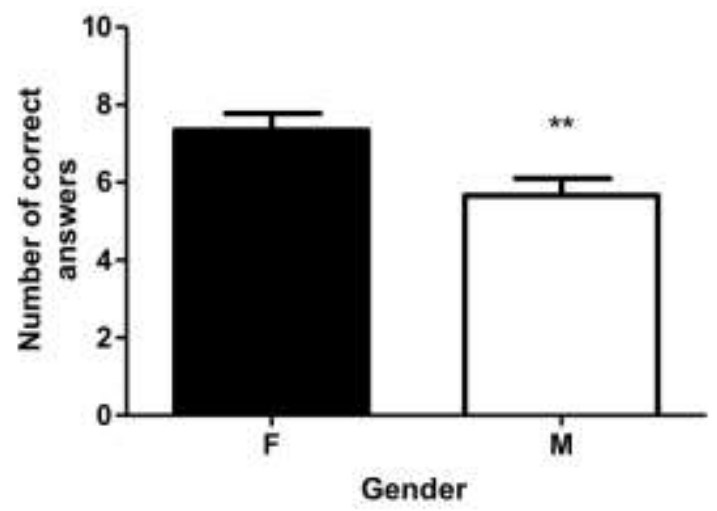

(a) Immediate Memory correct numbers between the genders, and (b) Late Memory correct numbers between the genders. Data expressed in the average of correct answers, Mann-Whitney test, values of $* p=0.045$ and $* * p=0.009$. Source: Authors.

\subsection{Visual memory through scrambled figures}

There was no significant difference regarding the results of the scrambled figures test considering the comparisons between age, gender and moments 1 and $2(\mathrm{p}>0.05)$.

\subsection{Perceptual speed through the dictated number addition test}

Males solved fewer problems than females for the ten dictated addition mathematical problems at the beginning of the period (F: $7.6 \pm 0.5$ vs M: $5.5 \pm 2.75 ; \mathrm{p}=0.03$ ) (Figure 6). 
Figure 6 - Total number of correct answers on the test Addition of dictated numbers between the female and male group at the beginning of the academic semester.

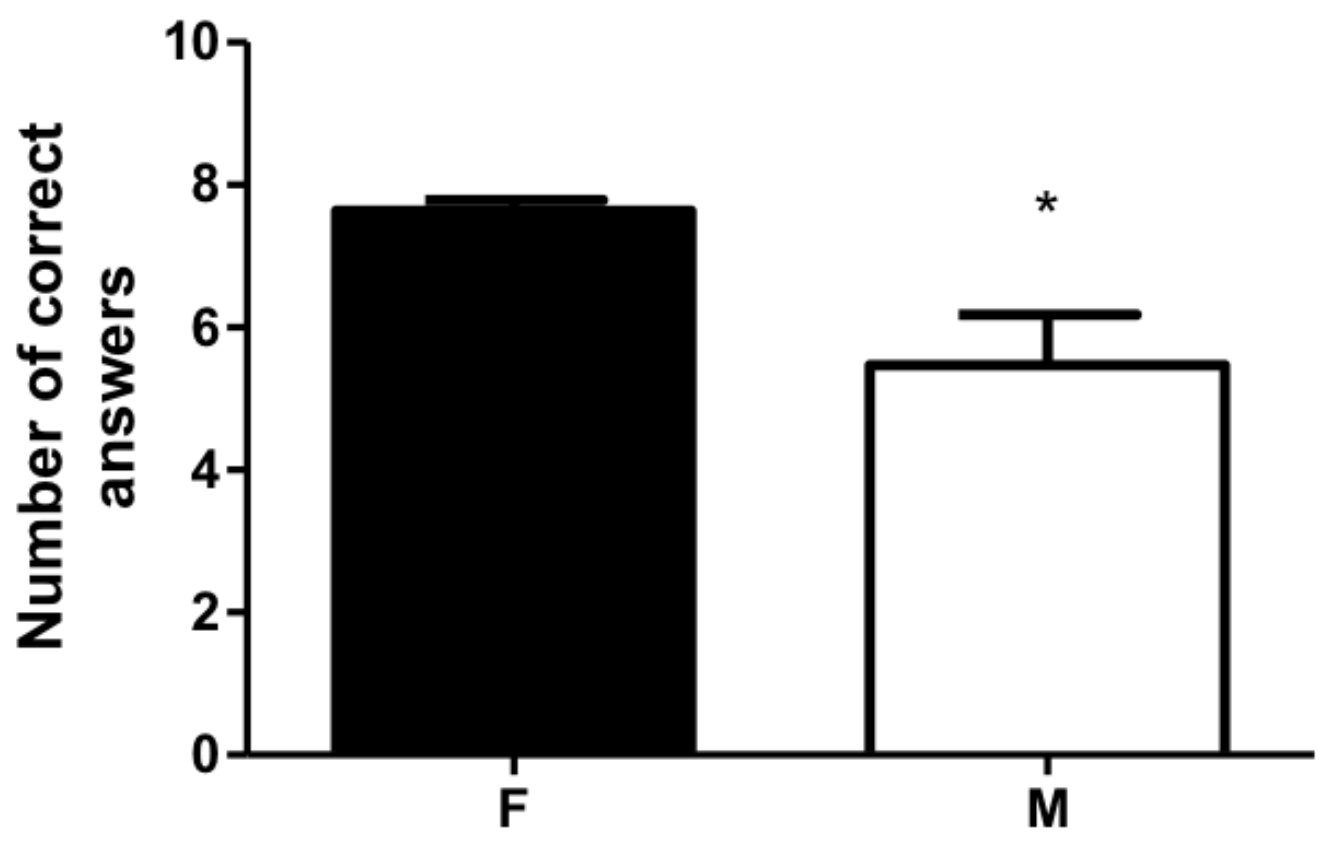

\section{Gender}

Data expressed in the average of correct answers, Mann-Whitney test $(* p=0.03)$. Source: Authors.

\subsection{The correlation between sleepiness and the object recall test}

The correlation between the level of sleepiness and the immediate memory of the figures of objects was insufficient ( $\mathrm{z}$ $=-0.21 ; p=0.14$, Pearson's correlation test $)$, as well as the delayed memory $(z=-0.15 ; p=0.33$, Pearson's correlation test $)$.

\section{Discussion}

The evidence from the present study showed that there was an abnormality in the degree of sleepiness at the end of the school semester. The boys had reduced immediate and late visual memories at the beginning of the school semester, showing difficulties in retaining visual memory. They also showed to have difficulties in the perceptual speed in the addition of dictated numbers test, having a lower performance than the girls. In turn, the girls showed a lower efficiency in late visual memory at the end of the school semester.

Thus, a degree of abnormal daytime sleepiness among children and adolescents can be identified as worrying, as evidence indicates that excessive sleepiness in this development period may be associated with inadequate sleep (Matricciani et al., 2013). However, variables regarding the degree of sleep deficiency and physical and mental impairment in children have not yet been defined (Canet, 2010). However, a longitudinal study with children aged 4 to 6 years found that a short period of sleep can cause fatigue the next day, causing sedentary behavior (Uebergang et al., 2017). Such behavior leads children to decrease physical activity performance and prefer the use of screens, generating a vicious cycle.

In addition, studies on the socioeconomic relationship and sleep have shown that children with the lowest socioeconomic status had a shorter sleep duration, as well as reports of problems with sleep quality (Bagley et al., 2015; Joseph A. Buckhalt et al., 2007). The data in the present study were collected at a school in the municipal education system where families have a low socioeconomic status. Thus, there may be a relationship between the degree of daytime sleepiness and 
socioeconomic issues. This is because a lack of financial resources makes it difficult for families to maintain a comfortable environment for an ideal sleep, such as: individual, quiet, and dark rooms with adequate temperature.

Regarding the memory tests, the results of the Rey-Osterrieth Complex Figure showed that the participants obtained a low score on both the copy design and the evocation, but the evocation score was much lower than the copy. The time in which the children observed the figure may have influenced the evocation performance, since the copy latency time was short.

The object recall test showed that the boys had aworse immediate and delayed memory than the girls, but only at the beginning of the semester. It should be noted that the cards of the second moment (M2) were different from the cards of the first moment (M1). Therefore, the card used at the beginning of the semester may have facilitated the girls' memorization process through associative learning, since the chosen figures may be more present in their daily lives, as well as being involved with emotional experiences.

One study observed the effect of familiarization with the stimulus on the orientation response and its changes with age using two different types of visual symbols (Cycowicz, 2019). One type consisted of meaningful symbols which can be named and the second consisted of meaningless symbols that cannot be named. The results showed that family symbols were more remembered than unknown symbols in all age groups. However, children did better than teenagers and adults in remembering unfamiliar symbols. The study concluded that children became accustomed to the new symbols due to the spontaneous tendency of perceptual processing, creating representations which can be compared to the new stimuli (Cycowicz, 2019).

Part of our data corroborates the findings of Cycowicz (2019), as children had an easier time with the test of memorizing objects present in their daily lives in relation to the the Rey-Osterrieth complex figure test. However, our results showed that children did not get used to the Rey-Osterrieth complex figure, having a lower performance in evoking the figure and manifesting difficulty with new stimuli. However, this may have occurred due to the short time that the children received the figure stimulus for.

The recall test also showed that children obtained better results at the beginning of the school semester in terms of immediate memory. The number of objects recalled immediately was greater than the number of objects recalled after a threeminute interval, revealing that the children were unable to retain their memory for a short time. This may be due to the difficulty of maintaining attention due to interference from internal or external factors such as stress. One study evaluated memory coding in a simulated stress situation (Brand et al., 2018). The children had to tell a story to a jury using a microphone, before or after the memory tests. It was noticed that the stress situation before or after the application of the tests led children to decrease verbal and visual performance in delayed memory (Brand et al., 2018).

Guidance and inhibition capacities are functions which facilitate adapting to new stimuli, playing an important role in learning. Orienting yourself requires attention to the changes which are happening around you, being fundamental for survival. Similarly, inhibiting irrelevant stimuli to maintain attention is an essential action for the memorization process (Nussenbaum et al., 2019). Therefore, the children studied may have difficulties in these cognitive processes; however, it is necessary to carry out further studies on the subject to justify this hypothesis.

Another important issue is the fact that children spend most of the year in the classroom. They learn that important information is written on the board, making it easier for them to orient themselves through the board, having more difficulties to perform other functions in an environment with different stimuli (Nussenbaum et al., 2019).

When considering the comparisons between the genders, boys had a lower performance than girls in relation to immediate and late memory at the beginning of the school term. Studies that have evaluated memory so far have shown no differences in performance regarding gender for the 9-11 age group. However, even without finding a relationship between drowsiness and gender, studies have shown that boys are more likely to have sleep problems and poorer sleep hygiene 
practices than girls (Uebergang et al., 2017). Therefore, it is important to once again emphasize the importance of a more indepth sleep assessment.

Just as in visual memory, the mathematical problem solving test showed that boys underperformed girls compared to the perceptual speed test. Executive performance refers to the individual's ability to maintain a set of cognitive strategies for problem solving (Cruz et al., 2011). Therefore, the boys also had difficulties in maintaining attention, concentration and formulating strategies arising from auditory stimuli.

Thus, the results showed the need to apply other methods to complement the findings, such as the polysomnography, analysis of cortisol levels, application of other test batteries to assess memory, as well as other cognitive functions. In addition, it is necessary to apply the instruments in other times throughout the day, in other schools and municipalities.

Therefore, it is worth emphasizing the relevance of this study for the academic environment and society in general, since the results presented herein suggest a negative relationship between poor sleep hygiene and the memorization process of school-aged children. Knowledge about the biological rhythms of the human being, especially the circadian rhythm, is necessary to understand and respect the individual needs of each human being. Regarding the school environment, it is important to understand that reduced sleep time can have a negative impact on a student's school performance, breaking the stigma that napping in the classroom is purely due to the student's lack of interest, but other factors contribute to increase daytime sleepiness, such as poor sleep hygiene. Therefore, these factors can be taken into account when making a cognitive assessment. Furthermore, these intervening variables during child development may be predictors of changes in learning at later ages.

\section{Conclusion}

The data revealed that there is no direct influence of daytime sleepiness on visual memory with the tests used, however there is an abnormality in the degree of sleepiness at the end of the school semester. Furthermore, the children showed less visual perception efficiency with the applied test at the beginning of the school period, indicating that they may have greater difficulty in retaining memory. In addition, the girls had a better immediate and delayed memory. These changes in the efficiency of visual memory were dependent on the evaluation period, considering that the changes were observed at the beginning of the school semester. It is suggested that future research apply the tests at other times throughout the day and use techniques such as polysomnography, analysis of cortisol levels, and other test batteries to assess memory, as well as other cognitive functions.

\section{Acknowledgements}

We thank the director and teachers of the Mariana Amália Municipal School and the members of the research group Neural Plasticity, Environment and Behaviors (PLASMAC) of the Federal University of Pernambuco.

\section{References}

Bagley, E. J., Kelly, R. J., Buckhalt, J. A., \& El-Sheikh, M. (2015). What keeps low-SES children from sleeping well: The role of presleep worries and sleepenvironment. Sleep Medicine, 16(4), 496-502. https://doi.org/10.1016/j.sleep.2014.10.008

Bastos, J. L. D., \& Duquia, R. P. (2007). Um dos delineamentos mais empregados em epidemiologia: estudo transversal. Scientia Medica, 17(4), 229-232.

Bathory, E., \& Tomopoulos, S. (2017). Sleep Regulation, Physiology and Development, Sleep Duration and Patterns, and Sleep Hygiene in Infants, Toddlers, and Preschool-Age Children. Current Problems in Pediatric and Adolescent Health Care, 47(2), 29-42. https://doi.org/10.1016/j.cppeds.2016.12.001

Brand, S., Mikoteit, T., Kalak, N., Bahmani, D. S., Lemola, S., Gerber, M., Ludyga, S., Bossard, M., Pühse, U., Holsboer-Trachsler, E., \& Hatzinger, M. (2018). Cortisol impacted on explicit learning encoding, but not on storage and retrieval, and was not associated with sleep patterns-results from the Trier Social Stress Test for Children (TSST-C) among 9-years old children. Frontiers in Psychology, 9(NOV), 1-10. https://doi.org/10.3389/fpsyg.2018.02240 
Canet, T. (2010). Sleep-wake habits in Spanish primary school children. Sleep Medicine, 11(9), 917-921. https://doi.org/10.1016/j.sleep.2010.07.005

Cruz, V. L. P. da, Toni, P. M. de, \& Oliveira, D. M. de. (2011). As funções executivas na figura complexa de Rey: relação entre planejamento e memória nas fases do teste. Bol. psicol, 61(134), 17-30.

Cycowicz, Y. M. (2019). Orienting and memory to unexpected and/or unfamiliar visual events in children and adults. Developmental Cognitive Neuroscience, 36(April 2018), 100615. https://doi.org/10.1016/j.dcn.2019.100615

Diekelmann, S., \& Born, J. (2010). The memory function of sleep. Nature Reviews Neuroscience, 11(2), 114-126. https://doi.org/10.1038/nrn2762

Elliott, CD, Smith, P, Mcculloch, K. ([s.d.]). British ability scales second edition (BAS II).

Fadda, R., Rapinett, G., Grathwohl, D., Parisi, M., Fanari, R., Calò, C. M., \& Schmitt, J. (2012). Effects of drinking supplementary water at school on cognitive performance in children. Appetite, 59(3), 730-737. https://doi.org/10.1016/j.appet.2012.07.005

Gustafsson, M. L., Laaksonen, C., Aromaa, M., Asanti, R., Heinonen, O. J., Koski, P., Koivusilta, L., Löyttyniemi, E., Suominen, S., \& Salanterä, S. (2016). Association between amount of sleep, daytime sleepiness and health-related quality of life in schoolchildren. Journal of Advanced Nursing, 72(6), 1263-1272. https://doi.org/10.1111/jan.12911

Heins, E., Seitz, C., Schüz, J., Toschke, A. M., Harth, K., Letzel, S., \& Böhler, E. (2007). Schlafenszeiten, fernseh- und computergewohnheiten von grundschulkindern in Deutschland. Gesundheitswesen, 69(3), 151-157. https://doi.org/10.1055/s-2007-971061

Jamus, D. R., \& Mäder, M. J. (2005). A Figura Complexa de Rey e seu papel na avaliação neuropsicológica. Journal of Epilepsy and Clinical Neurophysiology, 11(4), 193-198. https://doi.org/10.1590/s1676-26492005000400008

Johns, M. W. (1991). A new method for measuring daytime sleepiness: The Epworth sleepiness scale. Sleep, 14(6), 540-545. https://doi.org/10.1093/sleep/14.6.540

Joseph A. Buckhalt, Mona El-Sheikh1, \& Peggy Keller. (2007). Children's Sleep and Cognitive Functioning: Race and Socioeconomic Status as Moderators of Effects. Child Development, 78(1), 213-231.

Lissak, G. (2018). Adverse physiological and psychological effects of screen time on children and adolescents: Literature review and case study. Environmental Research, 164(January), 149-157. https://doi.org/10.1016/j.envres.2018.01.015

Macchitella, L., Marinelli, C. V., Signore, F., \& Ciavolino, E. (2020). brain sciences Learning in Children.

Mah, C. D., Kezirian, E. J., Marcello, B. M., \& Dement, W. C. (2018). Poor sleep quality and insufficient sleep of a collegiate student-athlete population. Sleep Health, 4(3), 251-257. https://doi.org/10.1016/j.sleh.2018.02.005

Matricciani, L., Blunden, S., Rigney, G., Williams, M. T., \& Olds, T. S. (2013). Children's sleep needs: Is there sufficient evidence to recommend optimal sleep for children? Sleep, 36(4), 527-534. https://doi.org/10.5665/sleep.2538

Meyer, T., \& Rust, N. C. (2017). Single-exposure visual memory judgments are reflected in IT cortex. bioRxiv, 1-27. https://doi.org/10.1101/197764

Mourão, C. A., \& Faria, N. C. (2015). Memória. Psicologia: Reflexao e Critica, 28(4), 780-788. https://doi.org/10.1590/1678-7153.201528416

Nussenbaum, K., Scerif, G., \& Nobre, A. C. (2019). Differential Effects of Salient Visual Events on Memory-Guided Attention in Adults and Children. Child Development, 90(4), 1369-1388. https://doi.org/10.1111/cdev.13149

Pereira, A. S., Shitsuka, D. M., Parreira, F. J., \& Shitsuka, R. (2018). Metodologia da pesquisa científica.

Rasch, B., \& Born, J. (2013). About sleep's role in memory. Physiological Reviews, 93(2), 681-766. https://doi.org/10.1152/physrev.00032.2012

Sinha, S., Jhaveri, R., \& Banga, A. (2015). Sleep Disturbances and Behavioral Disturbances in Children and Adolescents. Psychiatric Clinics of North America, 38(4), 705-721. https://doi.org/10.1016/j.psc.2015.07.009

Tononi, G., \& Cirelli, C. (2014). Sleep and the Price of Plasticity. Neuron, 23(1), 1-7. https://doi.org/10.1016/j.neuron.2013.12.025.Sleep

Uebergang, L. K., Arnup, S. J., Hiscock, H., Care, E., \& Quach, J. (2017). Sleep problems in the first year of elementary school: The role of sleep hygiene, gender and socioeconomic status. Sleep Health, 3(3), 142-147. https://doi.org/10.1016/j.sleh.2017.02.006

van der Heijden, K. B., Stoffelsen, R. J., Popma, A., \& Swaab, H. (2018). Sleep, chronotype, and sleep hygiene in children with attention-deficit/hyperactivity disorder, autism spectrum disorder, and controls. European Child and Adolescent Psychiatry, 27(1), 99-111. https://doi.org/10.1007/s00787-017-1025-8

Wang, J. Y., Weber, F. D., Zinke, K., Noack, H., \& Born, J. (2017). Effects of sleep on word pair memory in children - separating item and source memory aspects. Frontiers in Psychology, 8(SEP), 1-9. https://doi.org/10.3389/fpsyg.2017.01533 